\title{
Robust Increased Capacity Image Steganographic Scheme
}

\author{
M. Khurrum Rahim Rashid \\ Department of Electrical \\ Engineering, NUSES FAST, \\ Pakistan
}

\author{
Nadeem Salamat \\ Department of Mathematics and \\ Statistics \\ Karakoram International University, \\ Gilgit
}

\author{
Saad Missen, Aqsa Rashid \\ Department of Computer Science \\ and Information technology, \\ the Islamia University of \\ Bahawalpur, Pakistan
}

\begin{abstract}
- with the rising tempo of unconventional right to use and hit protection of secret information is of extreme value. With the rising tempo of unconventional right to use and hit, protection of secret information is of extreme value. Steganography is the vital matter in information hiding. Steganography refers to the technology of hiding data into digital media without depiction of any misgiving. Lot of techniques has been projected during past years. In this paper, a new steganography approach for hiding data in digital images is presented with a special feature that it increases the capacity of hiding data in digital images with the least change in images perceptual appearance and statistical properties at too much less level which will be very difficult to detect.
\end{abstract}

Keywords-Image steganography, LSB, Security Analysis, Robustness Analysis

\section{INTRODUCTION}

The data that are passing on through internet persistently have possibility of third individual nosy. So there should be some criteria to keep information covert today as the current time is of digital contact. Steganography has established significant attention during the previous few years, in particular after anecdotal news suspected that this tool was used by terrorist. Steganography [2] [3] inquire about to make available a clandestine message control between two parties. There are various steganography [4] [5] technique and medium used for this purpose. These methods are gaining value due to the secret communication over the internet.

LSB substitution [1] and LSB matching method are the oldest methods of steganography. Both of these are applied on least significant bit and only one bit per pixel for grayscale and three bits per pixel for color image can be used for hiding message. During past years lot of techniques of steganography have been projected [4] [5] [8].

In this paper the advantages of LSB matching and LSB substitution are used and capacity is increased with least statistical and perceptual change. The paper is arranged as Section 2 describes Method, Section 3 discusses analysis of cases of change in pixel value, Section 4 compares the Substitution with the proposed method in term of change in pixel value, Section 5 is Compare by Analysis tools and Experimental results and discussion, Section 6 is the conclusion and references are in last section.

\section{METHOD}

In the proposed method the two operations are performed on one pixel. First the pixel value is adjusted in such a way that the second least significant bit becomes the message bit and after that substitution is performed on the least significant bit. This technique is applied on both the grayscale and color image.

\section{A. Description of the proposed Method}

The proposed system performs operations on second and least significant bit separately to improve the performance of simple substitution on least two bits of pixel. These can be described as:

1) Take two consecutive message bits Xi and $X_{i+1}$

2) For Xi, if second least significant bit is not same as $X i$, then increment and decrement in pixel value in such a way that second least bit becomes the message bit Xi.

3) For the $X_{i+1}$, if least significant bit in not same as $X_{i+1}$, then simply the least significant bit of pixel will be replaces by the message bit $X_{i+1}$.

\section{B. Description of the proposed Method}

1-Message bits $=X_{\mathrm{i}} \mathrm{X}_{\mathrm{i}+1}=00$

\section{Pixel Decimal $=4$}

\begin{tabular}{|c|c|c|}
\hline 00000100 & 00000100 & 00000100 \\
\hline Pixel & (b) Pixel binary & (c) Pixel binary \\
\hline Binary & $\begin{array}{l}\text { after } \\
\text { operation }\end{array}$ & after LSB operation \\
\hline
\end{tabular}

Transformation of pixel value from (a) to (b) require no change because they are before now the same. Same is the case with transformation of (b) to (c). It is concluded from this that it is a case of no change (NC).

2-Message bits $=X_{i} X_{i+1}=11$

Pixel Decimal=4

\begin{tabular}{|c|c|c|}
\hline 00000100 & 00000011 & 00000011 \\
\hline Pixel & (b) Pixel binary & (c) Pixel binary after \\
\hline Binary & $\begin{array}{l}\text { after } \\
\text { operation }\end{array}$ & LSB operation \\
\hline
\end{tabular}


Transformation of pixel value from (a) to (b) require decrement of 1 as message bit and pixel second least significant bit are not same. Transformation of (b) to (c) requires no change because they are before now the same. It is concluded from this that it is a case of change of $1(\mathrm{C}-1)$.

3-Message bits $=X_{\mathrm{i}} \mathrm{X}_{\mathrm{i}+1}=10$

Pixel Decimal $=4$

\begin{tabular}{llllr} 
& \multicolumn{1}{c}{0000011} & & 00000010 & \\
00000100 & 0000 & & \\
(a)Pixel Binary & (b) Pixel binary & (c) Pixel & binary \\
& after & SLSB & after & LSB \\
& operation & & operation &
\end{tabular}

Transformation of pixel value from (a) to (b) require decrement of 1 as message bit and pixel second least significant bit are not same. Transformation of (b) to (c) also creates decrement of 1 . So from (a) to (c) total change is 2 . It is concluded from this that it is a case of change of 2 (C-2).

4-Message bits $=X_{i} X_{i+1}=01$

Pixel Decimal $=4$

\begin{tabular}{llllr}
\hline 00000100 & 00000100 & & 00000101 & \\
\cline { 3 - 5 } & (b)Pixel & binary & (c) Pixel binary \\
(a)Pixel binary & after & SLSB & after & LSB \\
& operation & & operation &
\end{tabular}

Transformation of pixel value from (a) to (b) require no change. Transformation of (b) to (c) creates a change of 1 . So from (a) to (c) total change is 1 . It is concluded from this that it is a case of change of $1(\mathrm{C}-1)$.

\section{Formal steps for insertion process:}

Input: Cover Image CI and array of bit stream BS Output: Stego-Image SI

1. $P \leftarrow m$

2. $\quad i=0$

3. $l(n)=$ length $(B S)$

4. for $j=0, \ldots, \frac{l(n)}{2}$

a. $X_{i}$ and $X_{i+1}$ are two consective bits from $B S$

b.

$$
\begin{aligned}
& S L S B P_{j} \\
& \leftarrow \text { Second least significant bit of pixel } \\
& \text { c. if }\left(X_{i} \neq S L S B P_{j}\right)
\end{aligned}
$$

i.

Adjustment of pixel value so that $X_{i}$ $=S L S B_{j}$

\section{d. end if}

e.

$$
L S B P_{j}
$$

$\leftarrow$ least significant bit of pixel at $j$ location;

f. $\quad$ if $\left(X_{i+1} \neq L S B P_{j}\right)$

g. end if h. $i=i+2$;

5. end for

Where $l(n)$ is the length of message bits, BS is the array of bit stream that contain the message bits. For the grayscale images the loop of step 4 will run for half of the length of the message bits as one interval of loop will hide two message bits in one pixel. $X_{i}$ and $X_{i+l}$ are the two consecutive message bits from array of bit stream BS.

For color images the loop interval will be reduced as each interval of loop will hide six message bits in one loop interval in one pixel. In sub-step (a) and (b) of step 4, the second least significant bit and least significant bit will be computed for red, green and blue channel for one pixel. Similarly in sub-step c of step 4, six consecutive message bits will be taken from the bit stream for each interval of loop of step 3 and hide two bits in each red, green and blue channel and therefore sub-step (h) of step 4 will increment 6 instead of 2 in each interval of loop.

Adjustment steps are following:

1. if $\left(X_{i}=0\right.$ \&\& $\left.S L S B P_{j}=1\right)$

a. $\quad$ if $\left(P_{j}=255\right)$

b. else

$$
\text { i. } \quad P_{j} \leftarrow P_{j}-2 \text {; }
$$

i. $\quad$ if $\left(P_{j} \% 2=0\right)$

ii. else 1. $\quad P_{j} \leftarrow P_{j}-1$;

iii. end else 1. $P_{j} \leftarrow P_{j}+1$;

c. end else

2. else

d. end if

a. $\quad$ if $\left(P_{j}=0\right)$

b. else

i. $P_{j}=P_{j}-2$;

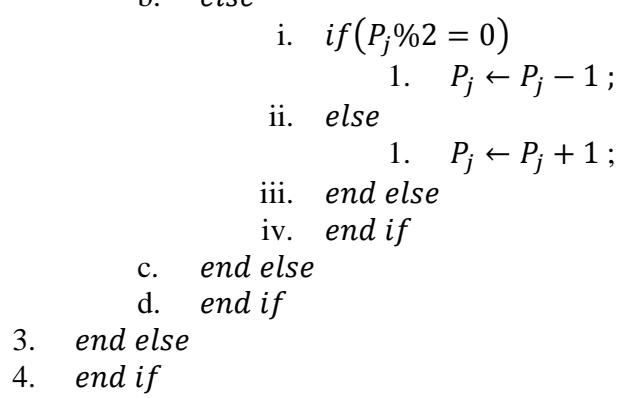

These steps just increment or decrement the pixel value in such a way that the second least significant bit becomes the message bit. Observation of all the 256 shades shows that there is $99.22 \%$ possibility that this change will be 1 and for only $0.78 \%$ it will be 2 .

\section{Formal steps for extraction process:}

While extraction, the loop will not end as long as at least two bits are collected as message bit from all pixels of the image. This is because the insertion is quite different from the retrieval process. We just recover the two LSBs value of each pixel and translate this to ASCII; the message will be 
understandable and in readable format up to the point that the message was inserted, and will then come into view as claptrap.

Input: Stego-Image

Output: Message

1. $P \leftarrow m$

2. for $j=0, \ldots, m$

a.

$$
L S B P_{j} \leftarrow
$$

Least significant bit of pixel at j location

b. if $\left(S L S B P_{j}==0\right)$

i. $B S \leftarrow 0$

c. else

i. $B S \leftarrow 1$

d. end else

e. end if

f. if $\left(L S B P_{j}==0\right)$

i. $B S \leftarrow 0$

g. else

i. $B S \leftarrow 1$

3. end for

h. end else

i. end if

In step $1 \mathrm{~m}$ is the total number of pixels in the image. $S L S B P$ and $L S B P$ are the least two significant bits of pixel $\mathrm{P}$ and $B S$ is the bit stream of message bits. After collecting all bits in $B S$, its ASCII conversion will give the message in readable format. If we know the length of the message that was inserted, then the loop will be ended when the length of message is completed and only the message will be retrieved i.e., no gibberish will be seen at the end of the message.

\section{E. Analyses of Cases of Change in Pixel Value}

This section makes analysis for all the shades of gray for checking the change in pixel value after the direct substitution and proposed method.

Table 1 shows the cases of change in all the gray shades for substitution method for two bits. Substitution method simply replaces the pixel's least two bits with the two message bits. For example if the two consecutive message bit are 11 and pixel binary is 11111101 . Then substitution simply replace 01 with $11,11111101 \rightarrow 11111111$. Replacement will be performed if the message bits and pixel's least bits are not same.

In Table I, first column is the gray level; second column is the binary of gray level, third column shows the binary value after substitution of 00 , fourth column shows the possibility of $\mathrm{C}$ (Change) and $\mathrm{NC}$ (No Change) in gray level after substitution of 00 . C-1 means the gray level will have change of 1 after substitution, C-2 is a change of 2, C-3 is a change of 3 and $\mathrm{NC}$ means that gray level will remain same as before substitution. Similar to substitution of message bits 00 , column 5 and 6 shows the possibility of $\mathrm{C}$ or $\mathrm{NC}$ for the substitution of message bits 11 ; column 7 and 8 shows the possibility of $\mathrm{C}$ or $\mathrm{NC}$ for the substitution of message bits 10 and last two columns are for message bit 01 .

\section{F. Comprison of Substitution and Proposed Method}

From the Table II and IV it is clear that proposed method is better than direct substitution as possibility of C-3 have been decreased from $12.50 \%$ to $0.20 \%$ by increasing the possibility of $\mathrm{C}-1$ from $37.5 \%$ to $49.80 \%$. Change of 3 is a grater change as compare to 1 . Change of 1 is invisible to human eye and almost undetectable. So proposed method is better in terms that it decreases the possibility of 3 and increases the possibility of change of 1 .

TABLE.I. ChANGE AfTER Simple Substitution Method

\begin{tabular}{|c|c|c|c|c|c|c|c|c|c|}
\hline Value & $\begin{array}{c}\text { Binary of } \\
\text { Value }\end{array}$ & $\begin{array}{c}\text { For Message } \\
\text { Bits 00 }\end{array}$ & $\begin{array}{c}\text { C/NC } \\
00\end{array}$ & $\begin{array}{c}\text { For Message } \\
\text { Bits 11 }\end{array}$ & $\begin{array}{c}\mathrm{C} / \mathrm{NC} \\
11\end{array}$ & $\begin{array}{c}\text { For Message } \\
\text { Bits 10 }\end{array}$ & $\begin{array}{c}\mathrm{C} / \mathrm{NC} \\
10\end{array}$ & $\begin{array}{c}\text { For Message } \\
\text { Bits 01 }\end{array}$ & $\begin{array}{c}\text { C/NC } \\
01\end{array}$ \\
\hline 0 & 00000000 & 00000000 & $\mathrm{NC}$ & 00000011 & C-3 & 00000010 & $\mathrm{C}-2$ & 00000001 & C-1 \\
\hline 1 & 00000001 & 00000000 & $\mathrm{C}-1$ & 00000011 & $\mathrm{C}-2$ & 00000010 & C-1 & 00000001 & $\mathrm{NC}$ \\
\hline 2 & 00000010 & 00000000 & $\mathrm{C}-2$ & 00000011 & $\mathrm{C}-1$ & 00000010 & $\mathrm{NC}$ & 00000001 & $\mathrm{C}-1$ \\
\hline 3 & 00000011 & 00000000 & $\mathrm{C}-3$ & 00000011 & $\mathrm{NC}$ & 00000010 & $\mathrm{C}-1$ & 00000001 & $\mathrm{C}-2$ \\
\hline 4 & 00000100 & 00000100 & $\mathrm{NC}$ & 00000111 & C-3 & 00000110 & $\mathrm{C}-2$ & 00000101 & $\mathrm{C}-1$ \\
\hline 5 & 00000101 & 00000100 & C-1 & 00000111 & C-2 & 00000110 & C-1 & 00000101 & $\mathrm{NC}$ \\
\hline 6 & 00000110 & 00000100 & C-2 & 00000111 & C-1 & 00000110 & $\mathrm{NC}$ & 00000101 & C-1 \\
\hline 7 & 00000111 & 00000100 & C-3 & 00000111 & $\mathrm{NC}$ & 00000110 & C-1 & 00000101 & $\mathrm{C}-2$ \\
\hline . & . & . & . & $\cdot$ & . & . & . & . & . \\
\hline 248 & 11111000 & 11111000 & $\mathrm{NC}$ & 11111011 & C-3 & 11111010 & $\mathrm{C}-2$ & 11111001 & $\mathrm{C}-1$ \\
\hline 249 & 11111001 & 11111000 & C-1 & 11111011 & C-2 & 11111010 & C-1 & 11111001 & NC \\
\hline 250 & 11111010 & 11111000 & $\mathrm{C}-2$ & 11111011 & C-1 & 11111010 & $\mathrm{NC}$ & 11111001 & $\mathrm{C}-1$ \\
\hline 251 & 11111011 & 11111000 & $\mathrm{C}-3$ & 11111011 & $\mathrm{NC}$ & 11111010 & C-1 & 11111001 & $\mathrm{C}-2$ \\
\hline 252 & 11111100 & 11111100 & $\mathrm{NC}$ & 11111111 & C-3 & 11111110 & $\mathrm{C}-2$ & 11111101 & $\mathrm{C}-1$ \\
\hline 253 & 11111101 & 11111100 & C-1 & 11111111 & $\mathrm{C}-2$ & 11111110 & C-1 & 11111101 & $\mathrm{NC}$ \\
\hline 254 & 11111110 & 11111100 & $\mathrm{C}-2$ & 11111111 & C-1 & 11111110 & $\mathrm{NC}$ & 11111101 & C-1 \\
\hline 255 & 11111111 & 11111100 & C-3 & 11111111 & $\mathrm{NC}$ & 11111110 & C-1 & 11111101 & $\mathrm{C}-2$ \\
\hline
\end{tabular}

Table II shows the conclusion of Table I. 
TABLE.II. Change After Simple Substitution Method

\begin{tabular}{|c|c|c|c|c|c|}
\hline Total Gray Levels & NC (No Change) & C-1 (Change of 1) & C-2 (Change of 1) & \multicolumn{2}{|c|}{ C-3 (Change of 1) } \\
\hline 256 for 00 & 64 & 64 & 64 & \multicolumn{2}{|c|}{64} \\
\hline 256 for 11 & 64 & 64 & 64 & \multicolumn{2}{|c|}{64} \\
\hline 256 for 10 & 64 & 128 & 64 & & \\
\hline 256 for 01 & 64 & 128 & 64 & & \\
\hline \multicolumn{6}{|c|}{ Total: } \\
\hline 1024 & 256 & & & 256 & 128 \\
\hline \multicolumn{6}{|c|}{ Average: } \\
\hline $100 \%$ & $25 \%$ & & & $25 \%$ & $12.5 \%$ \\
\hline
\end{tabular}

Table III shows the cases of change for proposed method.

TABLE.III. Change After Purposed Method

\begin{tabular}{|c|c|c|c|c|c|c|c|c|c|}
\hline Value & $\begin{array}{c}\text { Binary of } \\
\text { Value }\end{array}$ & $\begin{array}{c}\text { For Message } \\
\text { Bits 00 }\end{array}$ & $\begin{array}{c}\mathrm{C} / \mathrm{NC} \\
00\end{array}$ & $\begin{array}{c}\text { For Message Bits } \\
11\end{array}$ & $\begin{array}{c}\mathrm{C} / \mathrm{NC} \\
11\end{array}$ & $\begin{array}{c}\text { For Message Bits } \\
10\end{array}$ & $\begin{array}{c}\mathrm{C} / \mathrm{NC} \\
10\end{array}$ & $\begin{array}{c}\text { For Message Bits } \\
01\end{array}$ & $\begin{array}{c}\text { C/NC } \\
01\end{array}$ \\
\hline 0 & 00000000 & 00000000 & $\mathrm{NC}$ & 00000011 & C-3 & 00000010 & $\mathrm{C}-2$ & 00000001 & $\mathrm{C}-1$ \\
\hline 1 & 00000001 & 00000000 & C-1 & 00000011 & $\mathrm{C}-2$ & 00000010 & C-1 & 00000001 & $\mathrm{NC}$ \\
\hline 2 & 00000010 & 00000000 & $\mathrm{C}-2$ & 00000011 & $\mathrm{C}-1$ & 00000010 & $\mathrm{NC}$ & 00000001 & $\mathrm{C}-1$ \\
\hline 3 & 00000011 & 00000000 & $\mathrm{C}-1$ & 00000011 & $\mathrm{NC}$ & 00000010 & C-1 & 00000001 & $\mathrm{C}-2$ \\
\hline 4 & 00000100 & 00000100 & $\mathrm{NC}$ & 00000111 & $\mathrm{C}-1$ & 00000110 & $\mathrm{C}-2$ & 00000101 & $\mathrm{C}-1$ \\
\hline 5 & 00000101 & 00000100 & $\mathrm{C}-1$ & 00000111 & $\mathrm{C}-2$ & 00000110 & $\mathrm{C}-1$ & 00000101 & $\mathrm{NC}$ \\
\hline 6 & 00000110 & 00000100 & C-2 & 00000111 & C-1 & 00000110 & $\mathrm{NC}$ & 00000101 & $\mathrm{C}-1$ \\
\hline 7 & 00000111 & 00000100 & $\mathrm{C}-1$ & 00000111 & $\mathrm{NC}$ & 00000110 & C-1 & 00000101 & $\mathrm{C}-2$ \\
\hline & & & . & & & & . & & . \\
\hline 248 & 11111000 & 11111000 & NC & 11111011 & C-1 & 11111010 & C-2 & 11111001 & $\mathrm{C}-1$ \\
\hline 249 & 11111001 & 11111000 & C-1 & 11111011 & $\mathrm{C}-2$ & 11111010 & $\mathrm{C}-1$ & 11111001 & $\mathrm{NC}$ \\
\hline 250 & 11111010 & 11111000 & $\mathrm{C}-2$ & 11111011 & $\mathrm{C}-1$ & 11111010 & $\mathrm{NC}$ & 11111001 & $\mathrm{C}-1$ \\
\hline 251 & 11111011 & 11111000 & C-1 & 11111011 & $\mathrm{NC}$ & 11111010 & C-1 & 11111001 & $\mathrm{C}-2$ \\
\hline 252 & 11111100 & 11111100 & $\mathrm{NC}$ & 11111111 & $\mathrm{C}-1$ & 11111110 & $\mathrm{C}-2$ & 11111101 & $\mathrm{C}-1$ \\
\hline 253 & 11111101 & 11111100 & C-1 & 11111111 & $\mathrm{C}-2$ & 11111110 & C-1 & 11111101 & $\mathrm{NC}$ \\
\hline 254 & 11111110 & 11111100 & $\mathrm{C}-2$ & 11111111 & $\mathrm{C}-1$ & 11111110 & $\mathrm{NC}$ & 11111101 & $\mathrm{C}-1$ \\
\hline 255 & 11111111 & 11111100 & C-3 & 11111111 & $\mathrm{NC}$ & 11111110 & C-1 & 11111101 & $\mathrm{C}-2$ \\
\hline
\end{tabular}

CONCLUSION FROM TABLE 3:

Table 4 shows the conclusion of Table 3 .

TABLE.IV. Change AFter Proposed Method

\begin{tabular}{|c|c|c|c|c|}
\hline Total Gray Levels & NC (No Change) & C-1 (Change of 1) & C-2 (Change of 1) & C-3 (Change of 1) \\
\hline 256 for 00 & 64 & 127 & 64 & 1 \\
\hline 256 for 11 & 64 & 127 & 64 & 1 \\
\hline 256 for 10 & 64 & 128 & 64 & \\
\hline 256 for 01 & 64 & 128 & 64 & \\
\hline \multicolumn{5}{|c|}{ Total: } \\
\hline 1024 & 256 & 510 & 256 & 2 \\
\hline \multicolumn{5}{|c|}{ Average: } \\
\hline $100 \%$ & $25 \%$ & $49.80 \%$ & $25 \%$ & $0.20 \%$ \\
\hline
\end{tabular}

\section{COMPARISON BY ANALYSES TOOLS AND} EXPERIMENTAL RESULTS

This section discusses the "Comparison and Analysis tools" used to test the proposed method.

\section{A. Comparison and Analyses Tools}

The comparison section is further subdivided into two sections. First is named as "Security Analysis" and second is named as "Robustness Analysis".

\section{B. Security Analyses}

Comparing the histograms of cover image and the stegoimage gives the clear idea of security. The security examination evaluates the cover image with the stego-image on the basis of histograms of Images. For histogram comparison Correlation, Chi-square, Intersection and Bhattacharya distance [6] are computed between the histogram of cover image and stego-image.

All these comparisons are performed on normalized histogram. The correlation value varies between 1 and -1 . Perfect match is 1 and total mismatch is -1 . For Chi-square 
ideal value is 0 and mismatch value is unbound, for intersection 1 is ideal matching value and 0 is mismatched value and Bhattacharya distance gives 0 for the exact match and 1 for mismatch. When these comparison matrices gives ideal values or values that are closer to ideal values then the change in histogram is very least and this is the evidence for Stego-System to be a secure system.

\section{Robustness Analyses}

Robustness of any method depends on different parameters. In the paper four most important and widely used Image quality measures [7, 9, 10, 11, 12 and 13] namely MSE, PSNR, UIQI and SSIM are computed for comparison.

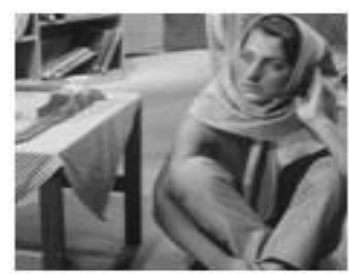

(a) Barbara Gray

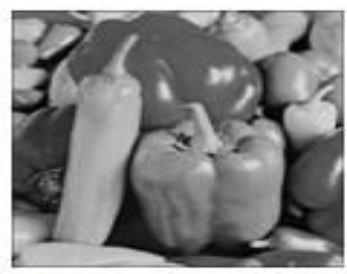

(b)Pepper Gray
Fig. 1. Images used for Test

Mean Square Error computes the perceived error. It is pixel value difference based quality measure. Peak Signal to Noise Ratio [10] is inversely proportional to MSE. Less MSE gives High PSNR which is the proof of the fact that image has good quality.

Image Quality Index split the judgment of similarity between Cover Image (CI) and Stego-Image (SI) into three comparisons: Luminance, Contrast and Structural Information.

SSIM estimates "Perceived change in structural information". It computes the similarity between two images of common size. Its mathematical definition is as:

The value of UIQI and SSIM varies between 1 and -1 . Closer the highest positive value denotes too much less change in two images and -1 shows totally mismatch. UIQI and SSIM are considered as more consistent and accurate than MSE and PSNR.

\section{EXPERIMENTAL RESULTS}

This section presents the experimental results obtained after implementing the proposed method in .NET Framework (C\#). A system is designed and implemented in .NET Framework (C\#) that shows the functioning of projected Increased Capacity Image Steganography method. The system is named as Robust Increased Capacity Image Steganographic Scheme (RICISS) because of exceptional results of Security Analysis and Robust analysis.

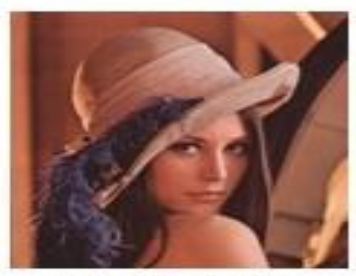

(c) Lena Color

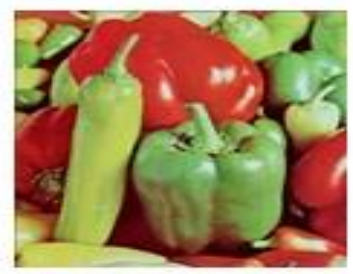

(d) Pepper Color
The proposed method is tested on many standard images. Some from the tested database are shown in Figure 1. (a) is the Barbara grayscale image having dimensions 512x512, (b) is the Pepper grayscale image having dimensions $512 \times 512$, (c) is the Lena color Image having dimensions 512×512 and (d) is the Pepper color image having dimensions $225 \times 225$.

The section also divided into two subsections. First will give the experimental results for grayscale images and second subsection will give for color images.

\section{A. Grayscale Image}

In Barbara Gray Image, Figure 1 (a), different numbers of bits are hidden and results are computed between cover and stego image. Table 5 shows the result of security analysis with 30272 bits of hidden data, 41472 bits of hidden data and 63824 bits of hidden data. Table 6 shows the results of robustness analysis for cover and stego Barbara Gray images.

TABLE.V. Result of SECURITy ANALySIS FOR THE BARBARA GRAy IMAGE

\begin{tabular}{|c|c|c|c|c|}
\hline Image & Method & 30272 Bits & 41472 Bits & 63824 Bits \\
\hline \hline Barbara Gray & Correlation & 0.99999 & 0.99998 & 0.99997 \\
\hline Barbara Gray & Chi-Square & 0.00032 & 0.00044 & 0.00068 \\
\hline Barbara Gray & Intersection & 0.99979 & 0.99971 & 0.99956 \\
\hline Barbara Gray & Bhattacharyya & 0.00089 & 0.00104 & 0.00139 \\
\hline
\end{tabular}

TABLE.VI. RESUlT OF ROBUSTNESS ANALYSIS FOR THE BARBARA GRAY IMAGE

\begin{tabular}{|c|c|c|c|c|}
\hline Image & Robustness Analysis IQM & 30272 Bits & 41472 Bits & 63824 Bits \\
\hline Barbara Gray & MSE & 0.07542 & 0.10348 & 0.15983 \\
\hline Barbara Gray & PSNR & 59.44863 & 58.07538 & 56.18712 \\
\hline Barbara Gray & UIQI & 0.99998 & 0.99998 & 0.99997 \\
\hline Barbara Gray & MSSIM & 0.99998 & 0.99998 & 0.99997 \\
\hline
\end{tabular}


In Pepper Gray Image, Figure 1 (b), different numbers of bits are hidden and results are computed between cover and stego image. Table 7 shows the result of security analysis with
24880 bits of hidden data, 41472 bits of hidden data and 55952 bits of hidden data. Table 8 shows the results of robustness analysis for cover and stego Pepper Gray images

TABLE.VII. RESUlt OF SECURITY ANALYSIS FOR THE PEPPER GRAy IMAGE

\begin{tabular}{|c|c|c|c|c|}
\hline Image & Method & $\mathbf{2 4 8 8 0}$ Bits & 41472 Bits & 55952 Bits \\
\hline \hline Pepper Gray & Correlation & 0.99999 & 0.99998 & 0.99997 \\
\hline Pepper Gray & Chi-Square & 0.00028 & 0.00046 & 0.00062 \\
\hline Pepper Gray & Intersection & 0.99993 & 0.99971 & 0.99961 \\
\hline Pepper Gray & Bhattacharyya & 0.00302 & 0.00336 & 0.00352 \\
\hline
\end{tabular}

TABLE.VIII. RESULT OF ROBUSTNESS ANALYSIS FOR THE PEPPER GRAY IMAGE

\begin{tabular}{|c|c|c|c|c|}
\hline Image & Robustness Analysis IQM & 24880 Bits & 41472 Bits & 63824 Bits \\
\hline \hline Pepper Gray & MSE & 0.07542 & 0.10348 & 0.15983 \\
\hline Pepper Gray & PSNR & 59.44863 & 58.07538 & 56.18712 \\
\hline Pepper Gray & UIQI & 0.99998 & 0.99998 & 0.99997 \\
\hline Pepper Gray & MSSIM & 0.99998 & 0.99998 & 0.99997 \\
\hline
\end{tabular}

\section{B. Color Image}

This subsection gives the experimental results for the color image. In Lena Color Image, Figure 1 (c), different numbers of bits are hidden and results are computed between cover and stego image. Table 9 shows the result of security analysis and robustness analysis with 66944 bits of hidden data and 81296 bits of hidden data in cover image.

TABLE.IX. RESUlt OF SECURITY AND ROBUSTNESS ANALYSIS FOR THE LENA COLOUR IMAGE

\begin{tabular}{|c|c|c|c|c|c|c|}
\hline Image & Method & $\mathbf{6 6 9 4 4}$ Bits & $\mathbf{8 1 2 9 6}$ Bits & Method & $\mathbf{6 6 9 4 4}$ Bits & 81296 Bits \\
\hline \hline Lena Color & Correlation & 0.99999 & 0.99999 & MSE & 0.06346 & 0.07723 \\
\hline Lena Color & Chi-Square & 0.00037 & 0.00044 & PSNR & 60.09989 & 59.26520 \\
\hline Lena Color & Intersection & 0.99975 & 0.99969 & UIQI & 0.99998 & 0.99997 \\
\hline Lena Color & Bhattacharyya & 0.00087 & 0.00098 & MSSIM & 0.99998 & 0.99997 \\
\hline
\end{tabular}

In Pepper Color Image, Figure 1 (d), different numbers of bits are hidden and results are computed between cover and stego image. Table 10 shows the result of security analysis and robustness analysis with 66944 bits of hidden data and 81296 bits of hidden

TABLE.X. RESUlt OF SECURITY AND RobustNess ANALYSIS FOR THE PEPPER COLOUR IMAGE

\begin{tabular}{|c|c|c|c|c|c|c|}
\hline Image & Method & $\mathbf{6 6 9 4 4}$ Bits & $\mathbf{8 1 2 9 6}$ Bits & Method & $\mathbf{6 6 9 4 4}$ Bits & 81896 Bits \\
\hline \hline Pepper Color & Correlation & 0.99992 & 0.99990 & MSE & 0.34794 & 0.41860 \\
\hline Pepper Color & Chi-Square & 59.44863 & 0.00214 & PSNR & 52.81439 & 51.99257 \\
\hline Pepper Color & Intersection & 0.99889 & 0.99963 & UIQI & 0.99993 & 0.99992 \\
\hline Pepper Color & Bhattacharyya & 0.00751 & 0.00756 & MSSIM & 0.99993 & 0.99992 \\
\hline
\end{tabular}

\section{CONCLUSIONS}

In this paper an increased capacity method of image steganography is presented and implemented for both the grayscale and color images. It makes accessible capacity improvement with least squalor in stego image quality. Experimental outcome be evidence for that the projected technique give good results for security analysis and robustness analysis and thus the projected technique provides the evidence to be strong.

\section{REFERENCES}

[1] N.F.Johnson, Sushil Jojadia George Mason University "Exploring Steganography: Seeing the Unseen", (0018-916/98/\$10.00@) IEEE, 1998

[2] R.Poornima, R.J.Iswarya, "An Overview of Digital Image Steganography", International Journal of Computer Science \& Engineering Survey (Vol.4, No 1) 2013

[3] T.Morkel, T.H.P.Eloff, M.S.Olivier, "An Overview of Image Steganography", ICSA Research Group, Department of Computer Science 
[4] Jammi Ashok, Y.Raju, S.Munishankaralak, K.Srinivas, Jammi Ashok, "Steganography: An Overview", et.01./International Journal of Engineering Science and Technology, (Vol.2 (10)), 2010, 5985-5992

[5] Shikha Sharda, Sumit Budhiraja , "Image Steganography:A Review", International Journal of Emerging Technology and Advance Engineering (volume 3, Issue 1), January 2013

[6] Asha, P. Nagabhushan, N. U. Bhajantri, "Similarity MEasures For Automatic Defect Detection ON PATTERned TeXtures", INTERNATIONAL JOURNAL OF IMAGE PROCESSING AND VISION SCIENCES (IJIPVS) VOLUME-1 ISSUE-1, 2012

[7] Rajkumar Yadav, "Analysis of Various Image Steganography Techniques Based Upon PSNR Metric", International Journal of P2P Network Trends and Technology- (Volume1, Issue2), ISSN: 2249-2615, 2011

[8] M. Pavani, S. Naganjaneyulu, C. Nagaraju, "A Survey on LSB Based Steganography Methods", International Journal of Engineering and Computer Science ISSN: 2319-7242 (Volume 2 Issue 8) Page No. 24642467, August, 2013

[9] Ismail Avcibas, Bulent Sankur, Khalid Sayood, "Statistical Evaluation of Image Quality Measure”, Journal of Electronic Imaging, 11(2), 206223(April 2002)

[10] Zhou Wang, Member,Hamid R. Sheikh, "Image Quality Assessment: From Error Visibility to Structural Similarity", IEEE Transactions On Image Processing, (VOL. 13, NO. 4), APRIL 2004

[11] Yousra A. Y. Al. Najjar, Dr. D. C. Soong, "Comparison of image quality assessment: PSNR, HVS, UIQI, SSIM”, IJSER, (Vol. 3, Issue8), ISSN2229-5518, August-2012

[12] Amhamed Saffor, Abdul Rahman Ramli, Kwan-Hoong Ng, "A Comparative Study of Image Compression between Jpeg and Wavelet", Malaysian Journal of Computer Science, (Vol. 14 No. 1), pp. 39-45, June 2001

\section{AUTHOR PROFILE:}

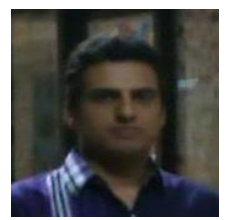

Muhammad Khurrum Rahim currently is a student of Electrical Engineering BS (EE) in NUSES FAST Islamabad, Pakistan for the session 2013-2017. He has won the competition of English Creative writing in 2007 held in Pano Akil Region, Pakistan by APS\&CS. He has one gold and three silver medals in Inter School Mega Competition 2012 and Inter School Mega Competition 2013 in Pano Akil Region, Pakistan by APS\&CS. His fields of interest include Robotics, Image Processing, Signal Processing, Circuit theory, Differential and Telecommunication

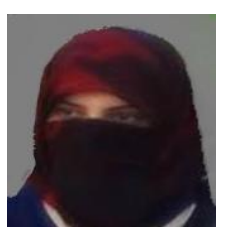

Aqsa Rashid received her Master's degree in Computer Sciences (MCS) (Gold Medalist) from Islamia of Bahawalpur, Pakistan in November, 2012. Currently she is a student of MSCS (session Feb, 2013-2015 spring) in Islamia University of Bahawalpur; Pakistan. She is a Visiting Faculty member of Islamia University of Bahawalpur, Department of CS\&IT since Nov, 2012 to present. Her fields of interest include Robotics, Digital image Processing, Artificial Intelligence, Data Mining and Web Designing and Development. At present, she is engaged in Image Steganography and Steganalysis.

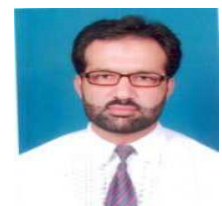

Saad Missen received his Masters degree (MSCS) in 2005 from University of Management and Technology, Lahore Pakistan. He received his Master of Research degree (M2R) in 2007 from University of Toulouse, France. $\mathrm{He}$ received his $\mathrm{PhD}$ degree in Computer Sciences in 2011 from University of Toulouse, France. Currently he is working as an Assistant Professor in Dept. of Computer Science \& IT, The Islamia University of Bahawalpur, Pakistan. His research interest includes Information Retrieval, Online Social Network Mining, Opinion Mining, Entity Retrieval, Usability Evaluation

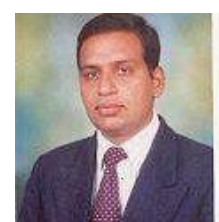

Nadeem Slamat received his MPhil degree in Informatics, Mathematics with specialty Image and Calculus from University of La Rochelle, 17000, FRANCE in 2008. He received his PhD degree in Image Understanding from University of La Rochelle, 17000, FRANCE in 2011.He is an HEC Approved $\mathrm{PhD}$ Supervisor. Currently he is working as an Assistant Professor in Karakoram International University, Gilgit Pakistan. His research interest includes Fuzzy sets, spatial logic, image understanding, Spatio-temporal Reasoning. 